\title{
Navigating the Academic Job Market Minefield
}

\author{
Ralph G. Carter, Texas Christian University \\ James M. Scott, University of Nebraska at Kearney
}

\begin{abstract}
As $s$ any recent job applicant can attest, the academic job market is tight. ${ }^{1}$ Many who have endured this market might paraphrase Thomas Hobbes in describing the job search process: "solitary, poor, nasty, brutish, and long." In this "buyer's market," the horror stories are widespread; 300 applicants for one tenure-track position at a Big 10 university, over 150 applicants for another position at a primarily undergraduate state university in the Midwest. The combination of an expanding applicant pool and a sluggish job market makes competition over academic positions both more fierce and more diffuse, as more and more institutions are able to be increasingly selective in their hiring, attracting candidates with impressive qualifications and prestigious degrees. ${ }^{2}$ As this trickles down, wellqualified individuals from lesserknown programs find competing for jobs even more difficult. ${ }^{3}$

Notwithstanding the above, the situation is far from hopeless. Candidates still enter the job market each year, and many get jobs. There are strategies and tactics candidates can employ that will help them as they begin their walk through the academic employment minefield. Here, we hope to begin a discussion of how academic job applicants might better their chances of landing that tenure-track position. Based on our recent experiences, respectively, as a department chair and as a search
\end{abstract}

committee member and job applicant, we would like to submit a few observations and suggestions-in a decidedly non-scholarly attempt to identify some things to do, and some things to avoid, while hunting for an academic position.

\section{Navigating the Job Market}

Because of the crowded job market, applicants must recognize that every search committee is interested in going about the difficult task of sorting through and evaluating this crowded applicant pool as conscientiously and efficiently as possible, and they will establish criteria to aid them in their efforts to get to a "short list" of interviewees. These "positive" criteria vary by position, institution, department, and committee, but almost certainly include some way to rank academic preparation, scholarship, teaching, and the amorphous category of "fit." Often, committees will also establish "negative" criteria to screen out candidates as quickly as possible (mismatched areas of specialization, unfulfilled degree requirements, missed deadlines, missing application materials, etc.). Therefore, there are a number of things an applicant can do to present a persuasive package that highlights the positive and avoids the negative criteria. After clearing these preliminary hurdles, a job applicant must then give a good
Ralph G. Carter is professor and former chair of the department of political science at Texas Christian University. A former president of the International Studies Association's Foreign Policy Analysis Section, he is coauthor of Making American Foreign Policy, with John Rourke and Mark Boyer (Dushkin/McGraw-Hill, 1996) and a contributor to After the End: Making U.S. Foreign Policy in the Post-Cold War World (Duke University Press, 1998).
James M. Scott is an assistant professor in the department of political science at the University of Nebraska at Kearney. He is author of Deciding to Intervene: The Reagan Doctrine and American Foreign Policy (Duke University Press, 1996) and a number of articles and book chapters on U.S. foreign policy, and editor and a contributor to After the End: Making U.S. Foreign Policy in the Post-Cold War World (Duke University Press, 1998). interview before the final hurdle is cleared. How to clear these hurdles? To try to help, we have organized a few of our personal "do's and don'ts" observations into the general categories of preparation, homework, application materials, and interviews. We are pleased to present these observations directly to job seekers and we invite others to share their thoughts.

\section{Preparation: Lay the Groundwork}

You can try to make yourself a very attractive candidate by building a strong foundation that rests primarily on three achievements. First, finish your dissertation. In a competitive buyer's market, there is simply no substitute for being done. ${ }^{4}$ Few departments will take risks with unfinished candidates when so many qualified individuals with degrees in hand are also applying. Short of being done, an ABD candidate should be able to provide the strongest possible assurances that his or her dissertation will be completed in the near future, including letters from dissertation advisers and drafts of multiple chapters. ${ }^{5}$ Second, get some independent teaching experience and call attention to it. In a crowded market, candidates with demonstrated independent classroom ability beyond that of a teaching assistant (i.e., as an instructor or visiting/adjunct professor) have an advantage. If you are at an institution that does not provide independent classroom responsibilities, try to acquire some in a neighboring institution as a part-time instructor. If it does not prevent you from completing your degree in a timely fashion, take a one-year, non-tenure appointment. Third, build a record of scholarship. Obviously, publications provide a distinct advantage, so all graduate students should plan accordingly. Those entering the job market with- 
out publications should, at a minimum, have a record of conference paper presentations and some pieces under review. A candidate with a degree in hand (or very close), independent teaching experience that shows classroom success, and a record of scholarly publication stands the best chance of making short lists in today's job market.

\section{Do Your Homework}

Before you prepare and submit your application packages, you should take great care to know the place to which you are applying. Doing your homework is time-consuming, but the investment of time is critical for a number of reasons. Such preparation helps you to determine what the employer really wants in the person who fills the position. Moreover, doing your homework helps you determine whether you are interested in and qualified for the position being advertised (i.e., whether you want the job). Further, your preparation of a persuasive application package depends greatly on the insight you gain from your "research" into the job opening. Finally, should the application lead to an interview, your homework will provide the basis for a much more effective interview performance. In short, doing your homework can make the difference between success and failure in today's crowded market, so you should find out all you can about the job in question, the university (and its locale), the department, and the faculty.

Your homework begins with the identification of job openings. By and large, such opportunities must be advertised, so you should canvas the advertising venues. In our field, the single best source of those job openings is the APSA Personnel Service Newsletter. Additional sources include The Chronicle of Higher Education, direct mailings to departments, the placement services of various conferences, and some association web pages. Do not engage in mass mailings of your vita to schools that have not advertised jobs. There are virtually no departments so overloaded with resources that they can create positions out of thin air, nor would doing so make sense given equal opportunity and affirmative action laws. Most departments are required by their own school's policies to engage in a well-publicized national search before filling any new tenure-track position.

Having identified an opening for which a search is being conducted, you should then devote some time to understanding the nature of the position. The first set of questions you need to ask concerns the broad characteristics of the job you are considering. What is the general nature of the institution? Is it in the "Top 25" category? A "Research I" institution? An undergraduate-only university or college? What does that tell you about your chances, your responsibilities if you were to get the job, and your level of interest (i.e., is that the kind of job you want? For which you are prepared?)? A little time spent answering these questions can prevent a major waste of time (both yours and theirs) later.

You should ask questions about the university and its location. What is the "role" or "mission" of the university or college? Is it a public or private institution? If public, how well is it funded? Does it have an endowment, or does it survive on its annual legislative appropriation and tuition revenues? Is it the flagship school of a state system (thus getting first claim on available state resources), or is it located much further down on the state's higher education food chain? If private, is there a religious affiliation? If so, what does that mean? Some private universities with religious affiliations openly give preference to faculty members and students sharing that religious viewpoint, and they may even require faculty to subscribe to key religious beliefs. At the same time, many universities with religious affiliations make no such demands on either faculty or students. If considering employment with a religiously-affiliated school, you need to know its policy on these matters. Don't assume the institution's name tells you all you need to know.

Whether public or private, does the university accept most high school graduates, or is admission offered on a more selective or competitive basis? Various guidebooks to U.S. colleges and universities can be found in most commercial bookstores, and these sources can tell you a lot about the types of students that attend a particular school. You can find out the average SAT scores of incoming students, the gender and racial composition of the student body, the percentage of students receiving financial aid, and so on. Will you be happy teaching and mentoring these students?

Don't forget about your off-campus life. What about the locale? Do you care for the climate, or is that important? Does the size of the city or urban area matter? Will the things that you value (e.g., family, mountains, oceans, cultural attractions, major regional airports, research opportunities, etc.) be near or far? How is the local economy? What about the local school systems? What makes an area attractive often lies in the eye of the beholder. Does a school's locale have what you want or need?

Finally, you ought to find out all you can about the department and the faculty. A good place to start is the relevant APSA guide, a department's homepage on the Internet, and the university's undergraduate and graduate catalogs, which may be available at your library. In addition, you should ask others if they have any insights into particular universities, departments, and/or faculty members. What do these people say about the department? What degrees does the department offerbachelor's, master's, or doctoral? What does that suggest in terms of your likely teaching responsibilities? If no graduate degrees are offered, is that a minus or a plus in your view? Would you be happy there? What about the faculty's individual credentials and characteristics? Where did they get their degrees? Do you look like a fit? If a department is composed of holders of doctoral degrees from the top 20 programs in the nation, will your degree fit that pattern? To the extent it does not, your application will probably be dis- 
carded very early in the screening process. Keep in mind that it is rare for individuals to be hired by a "higher-rated" university than the one that conferred their doctoral degree. There is a pecking order amongst universities, and you can husband your valuable time and resources by targeting the jobs you have the best chance to get. ${ }^{\circ}$

How much research does the faculty do? If they primarily write books, do they prefer academic presses over commercial ones? Do they primarily publish journal articles? If so, what journals do they prefer? Do most of them do the same types of research or employ similar research methodologies? If so, will your work fit in? If it doesn't, are you willing to contemplate changing what you study or how you study it? Can you keep up with your new colleagues if hired?

What about the diversity of the department? Departments with few women or minority members usually want to rectify that situation. A variety of groups provide assistance to women and minority candidates in the job search process, either by listing openings or by providing a database of relevant candidates, and those who qualify for such services should consider making these groups an integral part of the job search process. Some of these are listed in Table 1. On the other hand, departments that already have a diverse faculty could either be highly committed to furthering that diversity, or they may feel they have already satisfied that need.

\section{Prepare an Effective Application}

With the information you have accumulated, you can now turn to assembling the most persuasive package of materials possible. Remember what you are trying to do here: deliver a package of materials that demonstrates your credentials, your achievements, and your "fit" for the job, thus making you stand out as a particularly attractive candidate in what is likely to be a substantial pool of applicants. To have any chance of doing this persuasively and effectively, consider the following advice.

It sounds obvious, but give adequate consideration to the appearance, organization, and content of the package you are about to submit. Without being overly ostentatious, the package should be attractive and effectively organized, and the most relevant and important information that you want to convey should jump out at the reader who just "skims" the materials. Your letter, vita, and supporting materials should also be detailed enough to stand up to more rigorous second and third readings as committees whittle a group of candidates down to an interview pool. To increase your chances of making the short list, you should have a professionally organized and presented vita. Get a good template from an adviser or consult a professional, but make sure your vita presents your credentials well. Be certain to "build" it effectively and accurately as well; include-within the bounds of reason, common sense, and effective organization and presentation-as much detail as you can about your credentials, qualifications, and achievements. Do NOT "pad" your vita through misrepresentation or exaggeration. Be sure to include the right material with your vita. While the requirements vary from job to job, generally you will be asked to submit evidence of teaching and scholarly activity. Writing samples should include publications, dissertation chapters, conference papers, or papers under review, but you should probably not send seminar papers. If you submit teaching evaluations as a part of the first category, include summary pages that clearly present the overall results and provide a guide to the meaning of the (probably arcane) ratings your institution uses. Sample syllabi are good items to include, especially if they relate to the advertised teaching requirements of the position. For instance, if the job advertisement includes language to the effect that the person filling the position "will be expected to offer courses in...." you would probably be remiss if you did not include syllabi (and student evaluations) for such courses, assum- ing you have them. Lastly, when compiling your vita, consider attaching statements of teaching and research interests. Many places request such statements; including such items allows you to provide glimpses into your classroom philosophy and methods, as well as to describe a research agenda that promises continued scholarly activity. Such information can really help you stand out in an applicant pool.

Usually, only candidates who survive the first cut have their recommendation letters read carefully. Some of the best content analysis done in our profession is done in this applied setting. The readers look at what the letters say, what they don't say, and who is saying it. If the letters are ambiguous or raise other issues, members of the search committee might call or email the authors of the letters. Questions in follow-up contacts might range from "tell me more about candidate X" to "is there anything else we should know about $X$ that you preferred not to put in writing?"

Try to submit personalized recommendation letters, for they are the most effective. These letters talk about you as a potential teacher, scholar, and colleague. They give specific examples and relate anecdotes. They demonstrate that the author knows you, your work and experience, your strengths, and your credentials. Good letters build a persuasive case, thus requiring some work on the part of the writer. Moreover, good letters are also tailored to the position (for more on tailoring, see below). If you can get such assistance from those who recommend for you, ask them to incorporate some information or ideas that are especially relevant to a given job. Of course, this means you must provide those writing on your behalf some information about the job, the place, etc. Finally, update your letters as often as possible. Updating is especially important if you use a credential referral service. Make sure your recommendations (or, at least, the key ones) are as up-to-date as possible so they accurately reflect your current status, achievements, progress, etc. There is 
no reason not to allow those who recommend you to wax eloquent on your latest accomplishments. Remember that search committee members become disconcerted when something from an old letter ("soand-so will complete and defend the dissertation in January 1998") does not jive with a current letter of application ("I will defend my dissertation in September 1998").

Do everything you can to avoid sending form letters. These say something like "I know X. X studied under me. $X$ will do a fine job for you. I recommend X to you." You might be surprised at how many such letters search committees get. Unless written by a major figure in the appropriate subfield, they are virtually worthless. Even then, the candidate needs other letters to make a persuasive case.

The best mix of letters would include one from your major professor in graduate school (the lack of such a letter will be noticed, at least early in one's career), one or more from any other major individual(s) in your field of study, and at least one from someone who has worked closely with you and thus knows your strengths and weaknesses well. If you have teaching experience, such as a one-year position, try to include a letter from a key figure at that institution that comments on your teaching, collegiality, and scholarship (if possible).

How do you know what kinds of letters you will get? Talk to your closest mentors candidly about the letters. Ask them, and others ahead of you in your graduate program, if they know who writes good letters and who does not. Try to be realistic about your relationship with a possible letter writer and seek the help of those most likely to want to help you and those most likely to have the time to do so. Finally, when you request a letter, be candid. Ask the individual if they feel they are able to write the kind of letter that will be of the most assistance to you (while you are at it, ask if they would be willing to do the kind of tailoring described above, and be sure to give them enough lead time).

The c.v., letters of recommenda- tion, and appropriate supporting materials (syllabi, teaching evaluations, and writing/research samples) constitute the basic application package. However, there are several things to keep in mind as you submit this basic package to specific job openings. Above all, you should tailor your material to different positions. At a minimum, this means you should write a different cover letter for every position for which you apply. In that letter, highlight your degree of fit to the needs expressed in the job advertisement. Make it easy on search committee members by pointing out the ways that what you have done (or can do) meets the needs they have. ${ }^{7}$ For example, if you are applying to a university that places a higher priority on teaching than research, stress your teaching accomplishments or interests in the letter before extolling your commitment to an ongoing research agenda (or vice versa) and call attention to the match between your teaching experiences and capabilities and the courses and responsibilities of the position. Also keep in mind the fact that research universities are probably looking for specialists, while teaching colleges are more likely looking for people with greater substantive range. To whatever extent possible, indicate in the cover letter why the prospect of joining that faculty appeals to you. Simply put, you want to highlight your match to that place, and you want to show that you understand something about the particular place and the job that is being filled there. ${ }^{8}$ You can tailor other materials as well, including your statement of teaching interests (emphasize this statement at a teaching institution; fine-tune it to address the teaching needs at that particular place), research interests (add detail to this statement at research-oriented institutions), and the syllabi, evaluations, and writing samples you choose to send. Failure to do this tailoring may be fatal to an application.

Obviously, all of the above means that you carefully consider the merits of submitting a "canned application" of the type a number of institutions will help you generate. Such applica- tion packets may be convenient, but they clearly lack the specificity and tailoring described above. They may also convey the impression of a lack of care and interest in a specific job, thus establishing an additional hurdle that must be overcome to compete for the job successfully. ${ }^{9}$

At the same time, don't waste your time pursuing jobs for which you were not fully trained. Simply put, while it is very important to tailor your material for a specific position, do not "stretch" it. If a job description seeks someone in the public policy field and your major area of study is political philosophy, you will not survive the first cut. To cite another example, it's amazing how often candidates with specialties in other subfields think they can be competitive for American politics positions. As a rule, your dissertation should be in the subfield that constitutes the primary job requirement. Also, do not claim areas of secondary specialization if they are not borne out by your record. Many committee members will examine your transcripts to confirm that you have a training in comparative politics if the job asks for or you claim such a secondary emphasis. Even more specifically, particular emphases within a subfield are often equally important. If an international relations position demands a specialization in international law and organization, do not pretend to have it if your course work does not bear it out.

Moreover, it is imperative that you do not engage in overselling yourself. In the simplest sense, this means that, while you should highlight and call attention to those elements of your materials that make you a particularly strong candidate for the position, you should also refrain from pressing the issue too hard. Such overselling can leave the impression that you are either defensive about your credentials or arrogant about your achievements.

Avoiding the oversell also means you should make certain that your materials are scrupulously accurate, and that they do not leave false impressions. This warning should be unnecessary. However, some of our 
recent hiring experiences suggest that candidates can come perilously close to crossing the line. For example, some applicants in searches with which we are familiar presented themselves as broadly experienced teachers, while other aspects of their materials made it clear that this supposed wealth of experience was actually restricted to serving as a teaching assistant and/or discussion group leader. Of course, the discrepancy was discovered, which only undermined the credibility of the applicants with search committee members. Likewise, do not attempt to fudge or dissemble when it comes to the issue of the completion of your dissertation. Be honest and accurate in your assessment of what remains to be done and what has already been accomplished, and do not feel compelled to attach an "I plan to defend in. .." statement if it cannot be reasonably supported. Again, such an error may strike search committee members as a deliberate attempt to mislead.

We would also recommend that you take advantage of your advisors, mentors, and current colleagues (especially those who have served on search committees); have them review your application package before you submit it. Not only can this help you to prepare the strongest possible package, but it can also help you identify aspects of your package that need clarification, reorganization, or revision. Experienced colleagues can give you good advice on how "attractive" your application is, and they can help you avoid problems of "stretching" or "overselling." For instance, one of us was well-served by a colleague who reviewed his materials. Not only did that colleague help in the reorganization of his vita (to better present credentials and experience) but also helped fine-tune supporting materials and tone down a cover letter that pressed too hard. The changes made a difference in subsequent job competitions.

Finally, do everything in your power to get your package in on time and in good order. Allowing materials to straggle in bit by bit, with some elements possibly even being late, diminishes your chances in a search. Incomplete files are usually set aside to be taken up when (and if) they are complete. Unfortunately, the work of the search committee continues while such applications are tabled. If the material finally straggles in after a tentative short list is complete, members may be less interested in revisiting the application with the same kind of receptivity they may have afforded it at the outset. In the worst case, search committees will often discard all late applications, thereby reducing to a more reasonable number the applications to be considered.

In a related vein, do not antagonize a department chair or members of a search committee by repeatedly asking about the status of your candidacy. You might be surprised at how often this happens. Literally, the first or second applicant for the position will call and ask how they are faring even before the deadline for applications has arrived. Impatient applicants hurt their own cases. Otherwise credible candidates have been dropped from serious consideration after members of the search committee said something like: "I don't want to work with anyone that intense," or "This department doesn't need to add another person wound that tight." As a candidate, do yourself a favor: provide all requested information and then wait to be contacted. At most, you might call just before the deadline to ascertain whether all your materials are in and that the search committee has a complete file to review. Doing anything more makes you a pest.

\section{Give a Good Interview}

If you have done your homework and assembled your application package carefully, you have already gone a long way toward having a successful interview. When the ac- tual interviews come around, there are several things you can do to maximize your effectiveness and, subsequently, your chances of receiving a job offer. Remember that if you get an interview, that means that you are already considered qualified for the job. Hence, in addition to evaluating your teaching and scholarly potential, a major purpose of the interview is to gauge your fit and collegiality. Committee members will also be trying to determine how interested you are in the position. Therefore, you need to be able to display interest (without appearing overly eager) and convey the impression that you would be a good match. Moreover, you should also remember that interviewing truly begins from the time a short list phone call is made. Give some thought to how you would respond to these telephone calls.

When contacted for an interview, don't hesitate to inquire about what you will be asked to do during it. For example, a formal presentation of your current research to the department faculty is fairly standard, but a teaching-oriented college may ask you to lecture an undergraduate class as well. If the latter is the case, would you be ready? At this early point, you should also be prepared to ask some questions that demonstrate that you know something about the job and the place, and that you have a serious interest in the position (assuming, of course, that you do). Here again, doing your homework is critical.

Prior to arriving for the interview, anticipate the questions that might arise. Expect questions about your research agenda and your opinions regarding current issues of contention in your field. Don't be surprised by any question that aims to test your knowledge of what is going on in your field. You may also get asked what courses you have taught (or are prepared to teach) and what readings for them you have assigned 
(or would assign). You might be asked to defend those literature choices or explain why you have chosen not to use something else. What if the person asking such questions has published something in this subject area? Would you know, and how would you respond? You could be asked what you hope to accomplish in a particular course and how you would go about accomplishing it. You should be prepared to discuss your classroom and teaching philosophy, so have some articulate thoughts ready. What do you do in the classroom (or, better, in different types of classrooms), and how and why do you do it? In addition, you should be able to explain why you would like to work at that particular school (beyond "I need a job"). What is it you like about the employer? Why is it a match for your talents or interests? Finally, you should have questions that you want answered. Search committees and individual members will invite such questions; having none can be interpreted as an indication of a lack of interest or naiveté. Consider asking about departmental norms regarding classroom style, student advising, scholarly activity, and service. If you can, build and tailor questions from conversations during the interview as well.

Practice your interview performances. Utilize your department colleagues and other professional peers to simulate elements of your interview. Provide them with information about the job (gleaned from the advertisement and your homework) and ask them to play the role of a search committee. Nothing will help you iron out your presentation and anticipate questions and issues better than a good rehearsal.

Once your interview begins, you need to avoid two extremes. First, don't show you lack confidence. In the words of former Notre Dame football coach Lou Holtz, "When you get to the endzone, act like you've been there before." During the different phases of the interview, appearing relaxed, comfortable, and confident gives the impression that you are a teacher and a scholar and you know what you are doing. ${ }^{10} \mathrm{Sec}-$ ond, don't appear arrogant. If you convey the impression that you would be doing the department a favor by accepting the job, you are in trouble. Generally speaking, arrogant candidates don't get job offers unless they are very good (so others will be willing to put up with that arrogance) or the department is very large (so colleagues don't have to interact with the new person very much). Moreover, to your surprise, you might not actually be the "best" candidate applying for this position (refer back to the discussion about market realities above). Keep in mind that it is primarily you who is being interviewed. While it is important for you to try to get a sense of the place and your potential colleagues (after all, if the offer comes and you take it, you will have to live with your choice), you should be careful not to convey the impression that you are interviewing them. Finally, remember that no one owes you a position. In short, just because you have a degree from a top university or a couple of publications in the field's best journals, don't assume the offer of a tenure-track position is guaranteed. This behavior is most often seen on the part of candidates applying at schools they feel are "beneath them." Such attitudes may not always come through in cover letters, but they always come through in personal interviews.

Also, be careful of the sense of priorities you display. Ask questions about the job, its responsibilities, the department, the university, and the students before you ask how much the job pays, what benefits are included, or how big your office might be. Similarly, you should probably save your questions about promotion and tenure procedures for later in the interview. How you prioritize your questions reveals much about you. Self-centered questions are appropriate, but unless someone else brings these matters up, ask them late in the interview rather than early. In a slightly different vein, you should take care with the way you ask questions about teaching and research based on the type of institution at which you are interviewing. For instance, if your interview is at an undergraduate institution that emphasizes teaching, do not focus all your questions on research issues (or vice versa).

You can undermine your candidacy in other ways. For example, try not to say something that goes against the department's collective mindset. Criticizing rational choice theory, for instance, in a department where that is what most of the faculty do probably won't help one's chances. Similarly, one would not want to criticize internship programs, paralegal training, or any other type of program in which the department has heavily invested. While such mistakes may not be totally avoidable, careful homework about the department can limit such damage. Another problem can arise if you allow yourself to fall back on clichés and platitudes when asked substantive questions about your research interests or teaching philosophy. For instance, if you are being interviewed at a teaching institution, or one in which there is a rough balance between teaching and research expectations, questions about your classroom philosophy should not be answered with the obligatory "I try to get students involved," or "I believe in participation." You will be better off with specific responses and examples, especially if these are supported by your application materials and demonstrated during your classroom presentation. Again, remember that you are trying to show that you will fit in and contribute to the department.

Finally, you should remember that a major purpose of the interview is for the department to get a sense of you as a potential colleague. Hence, while the formal presentations are very important, keep in mind that you need to work on developing personal connections with the search committee members and other faculty. You should not get so bogged down in the formal components of the interview process that you forget to make these connections. Also remember that the interview is the time to be candid about yourself, your interests, your abilities, and your desire for the position. When you need a job, there is an enormous temptation to say you can or will do anything asked. Be careful not to commit to things you cannot do or to tasks you will hate. In case 


\section{Table 1}

\section{Women and Minority Personnel Contacts}

APSA Committee on the Status of Women in the Profession

Marian L. Palley, Department of Political Science, University of Delaware, Newark, DE 19716

American Association of Higher Education, Women's Caucus

1 Dupont Circle, NW \#360, Washinton, DC 20036

American Council on Education, Office of Women in Higher Education

1 Dupont Circle, NW \#800, Washington, DC 20036

APSA Committee on the Status of Blacks in the Profession

Sheila Ards, Chair, Humphrey Institute of Public Affairs, University of Minnesota, 252 Humphrey's Center, 301 19th Avenue South, Minneapolis, MN 55455; Ph: 612-625-9505, Fax: 612-625-63514; Email: sards@hhh.umn.edu

National Conference of Black Political Scientists Newsletter

Sheila Ards, Chair, Humphrey Institute of Public Affairs, University of Minnesota, 252 Humphrey's Center, 301 19th Avenue South, Minneapolis, MN 55455; Ph: 612-625-9505, Fax:612-625-63514; Email: sards@hhh.umn.edu

Black Faculty in Higher Education

Kennedy-King College, 6800 South Steward Avenue, Chicago, IL 60620

APSA Committee on the Status of Latinos in the Profession

Luis Fraga, Chair, Department of Political Science, Stanford University, Stanford, CA $94305-2044$

American Association of Higher Education Hispanic Caucus

1 Dupont Circle, NW \#360, Washington, DC 20036

National Indian Higher Education Association

University of New Mexico, 3045 Ferris Hall, Albuquerque, NM 87131; Ph: 505$277-6343$

Gay, Lesbian, Bisexual Political Science Caucus

Ohio University, Department of Political Science, Bentley Hall, Athens, $\mathrm{OH}$

45701-2979; Ph: 614-593-4373, Fax: 614-593-0394; Email:

huntr@oavaxa.cats.ohiou.edu

of the former, you will be setting yourself up for failure. In case of the latter, your time at that university will seem interminable, no matter how long or short it is.

\section{Some Thoughts if an Offer Comes}

Given the market, many candidates are happy to get any offer. Others approach this like a negotiation, believing they have more leverage before they join that department than they are likely to have thereafter. If you adopt this strategy, be careful to seek accommodations that seem reasonable in the context of that university or college; don't bar- gain your way out of a job. Academic employers rarely have much flexibility or discretion regarding entry-level salaries, particularly in the case of public universities. Compensation for moving expenses is rare. Some schools have reasonable amounts of research or travel support, while others can offer virtually none. Employment assistance for spouses also varies widely by school. As a new faculty member, you should expect to have a personal computer on your desk and an equal chance to receive any available research or travel support provided by the university. Beyond these minimums, the circumstances vary by situation. A good rule to follow is not to play hardball about what you "must" have, unless you are willing to lose the offer.

On the other hand, fight the temptation to accept a job you don't really want, working on the assumption that you'll leave after a couple of years. While this is hard advice to give, we have both faced the situation ourselves, and we have both made the very difficult decision to turn down a tenure-track offer without other offers in hand. Given the plethora of good candidates for positions at all ranks, chances are that you may be unable to leave that job. You may be stuck in that position for the rest of your career; keep this in mind. We all know people who have suffered this fate; don't add your name to the list. Ask yourself two questions: 1) Will I be content to stay here? and 2) Will this job provide the support and opportunities to do the things I need to do to move on if I so choose?"1

\section{Conclusion}

Some of the above may seem like a lot of "gloom and doom," but being realistic about the market can help you handle its ups and downs. Following the suggestions above will make you a more attractive applicant, thereby maximizing your chances for-getting your first academic position without stepping on landmines along the way. Just keep in mind that tenure-track positions increasingly require the Ph.D. in hand, teaching experience, and some publications. Be patient. Good candidates tend to get hired. You may have to broaden either the types of schools or locations considered. Further, you may have to spend some time in visiting positions to build up the teaching experience or have the time to get some publications into print. If you are willing to work hard and keep at it, an academic career is still a realistic goal in the twenty-first century. As a colleague has advised: "good people do get jobs ... eventually." 


\section{Notes}

1. This article flows from a roundtable discussion on the academic job market held at the October 1996 ISA-Midwest meeting held in St. Louis. The authors would like to thank Peter Longo, Joan Blauwkamp, and Diane Duffin for their helpful comments and suggestions.

2. For example, not long ago, a national search for a beginning assistant professor position at Texas Christian University produced an initial short list of 13 candidates. They ranged from ABDs from good doctoral programs to new Ph.D.s to senior assistant professors in tenure-track positions at other universities. All had teaching experience, and all had publications. Some of their publications were in very good journals, up to and including the American Political Science Review. A similar phenomenon occurred in recent searches at the University of Nebraska at Kearney, where the strength of the applicant pool allowed fine distinctions to be made in terms of specialization, teaching, research, and "fit." In both cases, therefore, the members of these undergraduate departments had the luxury to pick and choose exactly what they were looking for in a new colleague. Similarly, in both cases, some very competent candidates had to be stunned that they were not called for interviews or offered positions.

3 . This is not to say that all the advantages rest with candidates from the most prestigious universities. Well-trained and qualified candidates from smaller and lesser-know programs can succeed in today's market as well. While the competition is increasingly difficult, not all employers look for applicants from Top 20 doctoral programs. Concerns over the likelihood that a candidate will stay in a position, over the rele-

\section{References}

The Chronicle of Higher Education. 1995. September 22, A21.

"Departmental Rankings: Much Ado About vance and appropriateness of the type of training and socialization into the discipline a candidate has received, and over the congruence between the mission of a particular university or college and a candidate's expectations and objectives, lead many colleges to seek out good candidates from smaller programs.

4. On the relative success of candidates with degrees versus those still working, see Mann (1997).

5. In one recent search, for instance, the department and university needs/objectives and the strength of the applicant pool were such that the search committee was able to establish the criterion that any ABD candidate had to be able to submit three chapters of the dissertation to be included on the interview list.

6 . There are a number of published ratings of Ph.D. departments. Many have appeared in this journal. For example, see the June $1996 P S$ for its section entitled "Departmental Rankings: Much Ado about Something?" That issue includes a number of departmental rankings, including the 1993 National Research Council rankings, which can also be found in The Chronicle of Higher Education (1995).

7. If your degree is from a lesser-known program, you might also use the cover letter to provide some commentary on the nature and strengths of that program, especially in the context of why and how it prepared you for the job in question.

8. Of course, none of this advice will help you if your letter is poorly or carelessly written. You set back your application needlessly by failing to proof your letters. Allowing incorrect names, universities, position titles, and the like to appear (e.g., writing "the position at the University of ... appeals to me because" when that particular application goes to "__ State College," or incorrectly identifying the subfield focus of the position to which you are applying) can lead search committee members to reject your application out of hand.

9. Some canned applications include "nomination letters" in which a candidate is "formally" nominated by a graduate studies director or other individual from their doctoral institution. These letters can be a plus if interpreted by the search committee as a departmental vote of confidence in the applicant. However, such letters may be harmful if they appear presumptuous or arrogant. Certainly, they raise the question of whether the applicant is personally interested in taking the position.

10. Of course, ignorance or incompetence is itself a cause of self-destruction. Sometimes candidates who look great on paper come into an interview setting and can't answer simple, straightforward questions about their research subject or their subfield of study. Such candidates are not ready for the job market. No one wants to realize, two or three hours into a 48 hour interview, that the candidate doesn't know enough to be considered for the position.

11. You might think you can publish your way out of most jobs. Given the current buyer's market, however, and the tendency of some jobs to cut severely into your research and writing time with their expectations and responsibilities (not to mention their lack of support), this is less and less true.
Something?" 1996. PS: Political Science and Politics 29(2): 144-67.

Mann, Sheilah. 1997. "Placement of Political
Science Doctoral Students in 1996: Degrees Matter." PS: Political Science and Politics 30(3): 602-10. 